\title{
NUTRITIONAL PROFILE, ANTIOXIDANT, ANTIMICROBIAL POTENTIAL, AND BIOACTIVES PROFILE OF CHLORELLA EMERSONII KJ725233
}

\author{
SNEHA SUNIL SAWANT, VARSHA KELKAR MANE* \\ Department of Biotechnology, University of Mumbai, Kalina, Santacruz (E), Mumbai, Maharashtra, India. Email: drvkelkar@mu.ac.in \\ Received: 14 August 2017, Revised and Accepted: 05 December 2017
}

\section{ABSTRACT}

Objective: The present study revolved around the nutritional evaluation of Chlorella emersonii KJ725233, a novel non-fastidious Chlorella strain that was isolated from the Western regions of Maharashtra, India, for a probable use as a food supplement.

Methods: The nutritional composition of $C$. emersonii KJ725233 was evaluated in terms of total protein, total lipids, and total carbohydrates content along with its mineral composition. Furthermore, the effect of different solvents on the extraction of the bioactives and hence the antioxidant and antimicrobial activity of $C$. emersonii KJ725233 was also analyzed. The bioactives extracted in the organic solvents were further identified by gas chromatography-high-resolution mass spectrometry (GC-HRMS).

Results: As reported in the literature for commercial Chlorella powder, C. emersonii KJ725233 was found to contain an equivalent concentration of protein, three-fold lipid content, i.e. $36.48 \pm 0.52 \%$ and $43.58 \pm 0.72 \%$, respectively; along with $17.17 \pm 0.91 \%$ carbohydrates and $6.62 \pm 0.16 \%$ mineral content. Methanolic content was not only found to contain the highest antioxidant, radical scavenging potential as well as total phenolic content but also exhibited a strong antimicrobial potential against the tested Gram-positive, Gram-negative bacterial and fungal strains. Moreover, sterols, hydrocarbons, and fatty acid methyl esters known antimicrobials and antioxidants were identified when the organic extracts of the microalgae dried biomass were subjected to GC-HRMS analysis.

Conclusion: With a well-balanced nutritional composition together with the reservoir of antioxidants and antimicrobials, this native novel isolate of Chlorella thus emerges as a potential food supplement whose consumption would not only enhance the dietary value along with providing antiaging benefits.

Keywords: Chlorella emersonii KJ725233, Nutritional profile, Antioxidant, Antimicrobial, Gas chromatography-high-resolution mass spectrometry.

(C) 2018 The Authors. Published by Innovare Academic Sciences Pvt Ltd. This is an open access article under the CC BY license (http://creativecommons. org/licenses/by/4. 0/) DOI: http://dx.doi.org/10.22159/ajpcr.2018.v11i3.21990

\section{INTRODUCTION}

Chlorella is a widely commercialized eukaryotic green alga used as health food and feed supplement as well as in cosmetic and pharmaceutical applications [1]. Over 2500 tonnes of dried Chlorella is produced every year by the United States, Japan, China, Taiwan, and Indonesia [2]. For the myriad of its nutrients such as carotenoids, vitamins, and minerals, Chlorella biomass is packaged and marketed as tablets, capsules, powders, and liquids [3]. Commercial Chlorella production worldwide exceeds by four folds per tonne/year as compared to that of other microalgae like Dunaliella [4]. Chlorella biomass has been formulated in feed and food products to provide color effect as well as nutritional supplementation. Chlorella biomass has recently being used as an additive to fermented milk and yoghurt to enhance the viability of probiotic bacteria as well as in pasta products for improving its nutritional quality [5]. In addition to this, Chlorella vulgaris biomass was incorporated into butter cookies to give them an attractive appearance with improved textural characteristics with an unaltered taste [6].

Chlorella is primarily advertised for sale for the water-soluble Chlorella growth factor which exhibits a variety of health benefits such as increasing insulin sensitivity, strengthening immune system function, prevention of stress-induced ulcers, and pregnancy-associated anemia [4]. Chlorella is known to have the potential to relieve symptoms in people suffering from fibromyalgia, hypertension, and ulcerative colitis [2]. It is also an important health-promoting factor with an antitumor and preventive action against atherosclerosis and hypercholesterolemia [6].

Chlorella strains are cosmopolitan in occurrence due to their ability to adapt to a diverse range of habitats such as soil, freshwater lakes, ponds, marine as well as brackish waters in addition to the polar areas $[7,8]$. Due to the highest chlorophyll content, a fast growth rate coupled with its distribution over varied environmental conditions, Chlorella strains are considered as competent candidates for the synthesis of a diverse array of metabolic compounds [8-12]. To survive the inconsistent physical and chemical parameters, they have developed various adaptive and defensive mechanisms which include synthesis of a diverse array of metabolic compounds [13]. Due to the wide occurrence, rapid growth as well as nutritious qualities of Chlorella strains, a novel strain of the microalga was chosen for the present study to explore its potential as a food supplement.

A novel isolate, Chlorella emersonii KJ725233, has been isolated from a freshwater source from the Western region of Maharashtra, India [14]. In comparison to Chlorella vulgaris and Chlorella pyrenoidosa, two of the dominant Chlorella species currently in use in food industry which require specific growth requirements such as temperature as well as illumination conditions, C. emersonii KJ725233 is non- fastidious growing at temperatures ranging from 25 to $44^{\circ} \mathrm{C}$ [14-16]. Furthermore, an economical mass culturing method for fostering $C$. emersonii KJ725233 has been developed using low-cost cultivation media which can be reused with minimal energy inputs [14]. Thus, the present study deals with the determination of its nutritional as well as a biochemical composition along with the biological activity of the bioactives of a novel isolate - C. emersonii KJ725233.

\section{MATERIALS AND METHODS}

\section{Materials}

All the chemicals used were of analytical grade and were purchased from SD Fine-Chem Ltd., Mumbai, India. 2,2-diphenyl-2-picrylhydrazyl 
(DPPH), Mueller Hinton agar, nutrient broth, nutrient agar, Sabourauds broth (SAB), Sabourauds agar (SAB agar), and gentamicin were obtained from HiMedia, Mumbai, India. Fluka 150 mg (Cipla) was purchased from a local chemist, Mumbai.

\section{Methods}

\section{Microalga culturing}

C. emersonii KJ725233 was isolated from a freshwater source from the Western region of Maharashtra, India. It was identified morphologically as well as by $18 \mathrm{~s}$ rDNA sequencing [14]. The alga was mass cultured in $5 \mathrm{~L} \mathrm{BG}-11$ medium at $30 \pm 1^{\circ} \mathrm{C}$ with a $12 \mathrm{~h}$ photoperiod as well as aeration for a period of 30 days.

\section{Nutritional assessment of C. emersonii KJ725233}

After 30 days of growth, the biomass was harvested by centrifuging (Eppendorf, 5810R, Germany) the culture at $5000 \mathrm{rpm}$ for $20 \mathrm{~min}$. Nutritional composition of C. emersonii KJ725233 was determined in terms of its elemental composition, protein, lipid, and carbohydrate content. The moisture and ash content were determined gravimetrically by drying the biomass at $110^{\circ} \mathrm{C}$ and $550^{\circ} \mathrm{C}$, respectively, until constant weight was obtained [17]. The ash obtained was then subjected to acid digestion with aqua regia and analyzed by ICP-AES to determine the elemental composition [18]. The total protein content was determined by the Bradford's assay after extraction in $1 \mathrm{~N} \mathrm{NaOH} \mathrm{[19].} \mathrm{The} \mathrm{total} \mathrm{lipid}$ content was determined gravimetrically as previously described [20]. Carbohydrate levels were determined by anthrone-sulfuric acid method after extraction in $2.5 \mathrm{M} \mathrm{HCl}$ at $80^{\circ} \mathrm{C}$ for $3 \mathrm{~h}$ [17-21].

\section{Preparation of algal extracts}

Approximately $0.2 \mathrm{~g}$ of dried powder was suspended in distilled as well as organic solvents (methanol, acetone, chloroform, diethyl ether, and ethyl acetate) at a concentration of $0.1 \mathrm{~g} / \mathrm{ml}$. The suspensions were sonicated (LABMAN sonicator $40 \mathrm{~W}$ ) for $40 \mathrm{~min}$. The solutions obtained were centrifuged and supernatants pooled after three successive extractions. These were dried at $28 \pm 1^{\circ} \mathrm{C}$ and then reconstituted in absolute dimethyl sulfoxide (DMSO).

\section{Determination of in vitro antioxidant activity \\ Phosphomolybdenum assay}

The total antioxidant capacity (TAC) was determined by slight modifications in the previously described method [22]. To $30 \mu \mathrm{l}$ of the different solvent extracts, $300 \mu \mathrm{l}$ of TAC reagent $(0.6 \mathrm{mM}$ sulfuric acid, $28 \mathrm{mM}$ sodium sulfate, and $4 \mathrm{mM}$ ammonium molybdate) was added in 96-well microtiter plate and incubated in a water bath at $95^{\circ} \mathrm{C}$ for $90 \mathrm{~min}$. After incubation, the absorbance was read at $695 \mathrm{~nm}$. Ascorbic acid was used as a standard, and the TAC was expressed as mg ascorbic acid equivalent per $\mathrm{g}$ dried biomass (mg AAE/g DW). The tests were carried out in triplicates, and the values are expressed as mean $\pm \mathrm{SD}$.

\section{Ferric reducing antioxidant potential (FRAP)}

The reducing potential of the alga was evaluated by the potassium ferricyanide method according to standard procedure [23] with slight modifications. $125 \mu \mathrm{l}$ of $1 \%$ potassium ferricyanide was added to $50 \mu \mathrm{l}$ of the different solvent extracts in a 96-well microtiter plate and incubated at $50^{\circ} \mathrm{C}$ for $20 \mathrm{~min}$. After incubation, $125 \mu \mathrm{l}$ of $10 \%$ trichloroacetic acid was added and then $100 \mu \mathrm{l}$ of this reaction mixture was transferred to fresh wells to which an equal volume of distilled water was added. Finally, after addition of $20 \mu \mathrm{l}$ of $0.1 \%$ ferric chloride, the absorbance was read at $700 \mathrm{~nm}$. Ascorbic acid was used as a standard. The reducing potential was expressed as mg AAE per g dried biomass (mg AAE/g DW). The tests were carried out in triplicates, and the values are expressed as mean \pm SD.

\section{2,2-diphenyl-2-picrylhydrazyl radical scavenging activity (DPPH)}

Aliquots of $150 \mu \mathrm{L}$ of various concentrations $(2-10 \mathrm{mg} / \mathrm{ml})$ of the different solvent extracts were mixed with an equal volume of $0.2 \mathrm{mM}$ methanolic DPPH [24]. The reaction mixture was incubated in the dark at $28 \pm 1^{\circ} \mathrm{C}$ for $30 \mathrm{~min}$. After incubation, the absorbance was measured at $520 \mathrm{~nm}$. The free radical scavenging activity was then calculated as percentage inhibition by the following formula:

Percent inhibition $=\left[\left(\mathrm{A}_{\text {(blank) }}-\mathrm{A}_{\text {(test) }}\right) / \mathrm{A}_{\text {(blank })}{ }^{* 100}\right.$

IC50 $(\mathrm{mg} / \mathrm{ml})$ for the extracts was determined by plotting a graph of percentage inhibition against extract concentration. The tests were carried out in triplicates, and the values were expressed as mean \pm SD.

\section{Determination of total phenolic content}

The total phenolic content was studied by Folin-Ciocalteau method [25]. $25 \mu \mathrm{l}$ of $1 \mathrm{~N} \mathrm{FCR}$ was added to $50 \mu \mathrm{l}$ of the extracts followed by the addition of $125 \mu \mathrm{l}$ of saturated sodium carbonate. The reaction mixture was incubated in the dark at $28 \pm 1^{\circ} \mathrm{C}$ for $30 \mathrm{~min}$ after which the absorbance was measured at $765 \mathrm{~nm}$. The phenolic content was expressed as mg gallic acid equivalent per g dried biomass (mg GAE/g DW). The tests were carried out in triplicates and the values are expressed as mean $\pm \mathrm{SD}$.

\section{Determination of total flavonoid content}

The total flavonoid content was determined by the aluminum trichloride method [26]. In a 96-well microtiter plate, $150 \mu \mathrm{l}$ of $\%(\mathrm{w} / \mathrm{v}) \mathrm{AlCl}_{3}$ was added to an equal volume of the different solvent extracts and incubated in the dark at $28 \pm 1^{\circ} \mathrm{C}$ for $30 \mathrm{~min}$. After incubation, the absorbance was measured at $415 \mathrm{~nm}$. Quercetin was used as a standard with methanol as blank. The total flavonoids content was expressed as mg quercetin equivalent per g dried biomass (mg QE/g DW). The tests were carried out in triplicates and the values are expressed as mean \pm SD.

\section{Antimicrobial activity}

The antimicrobial activity of C. emersonii KJ725233 extracts was determined against Pseudomonas aeruginosa (MTCC 1688), Staphylococcus aureus (MTCC 6908), Bacillus subtilis (MTCC 441), Escherichia coli (MTCC 443), Candida albicans (MTCC 227), and Aspergillus niger (MTCC 1344) by the agar well-diffusion method. $1 \mathrm{mg} / \mathrm{ml}$ gentamycin was used as positive control for bacteria whereas $15 \mathrm{mg} / \mathrm{ml}$ fluconazole was used for yeast and fungi; DMSO was used as a negative control.

\section{Gas chromatography - high resolution mass spectrometry} (GC- HRMS) analysis

Qualitative analysis of all the organic extracts was carried out by GC- HRMS analysis using GC (Agilent Technologies, USA) equipped with AccuTOF. Compounds were separated on HP-5 MS capillary column having $5 \%$ phenyl polysiloxane as stationary phase with a column length of $30 \mathrm{~m}$, internal diameter $0.32 \mathrm{~mm}$, and film thickness $0.25 \mu \mathrm{m} .1 \mu \mathrm{l}$ of the sample was injected in the split ratio of 10:1, the injector and transfer line temperature was maintained at $250^{\circ} \mathrm{C}$ and $260^{\circ} \mathrm{C}$, while the ion source temperature was $200^{\circ} \mathrm{C}$. Oven temperature was programmed from 80 to $280^{\circ} \mathrm{C}$ with a rise of $10^{\circ} \mathrm{C} / \mathrm{min}$; flow rate of carrier gas helium was $1 \mathrm{ml} / \mathrm{min}$. Compounds were identified comparing their retention times and mass fragmentation patterns with the data of standards at the NIST library.

Table 1: Nutritional composition of Chlorella emersonii KJ725233

\begin{tabular}{lllll}
\hline Ash (\%) & Moisture (\%) & Proteins (g\%) & Lipids (g\%) & Carbohydrates (g\%) \\
\hline $6.62 \pm 0.16$ & $88.19 \pm 0.17$ & $36.48 \pm 0.52$ & $43.58 \pm 0.47$ & $17.17 \pm 0.91$ \\
\hline
\end{tabular}

Values are expressed as mean \pm SD for triplicate experiments. Values are significant at $\mathrm{P}<0.05$ 


\section{RESULTS AND DISCUSSION}

\section{Nutritional composition}

The nutritional value of $C$. emersonii KJ725233 was evaluated in terms of total lipids, proteins, carbohydrates as well as elemental composition and is presented in Table 1. The lipid content of the microalga was found to be $43.58 \mathrm{~g} / 100 \mathrm{~g}$ which is three folds that of a commercial Chlorella vulgaris powder as earlier reported. With a protein content equal to that of the commercial product; the alga under consideration scores over with its low carbohydrate content. Since algal carbohydrates are known to provide anticoagulants, antivirals, dietary fibers as well as antioxidants; a higher content is not preferred as greater quantities of carbohydrates correspond to lesser fractions of other macronutrients in the supplement, especially proteins [4].

The dietary ash content is important in terms of the minerals and trace elements it can provide; however, a low ash content $(<10 \%$ of the diet) is recommended in nutraceuticals due to the side effects it can cause. Ash content of $C$. emersonii KJ725233 as represented in Table 1 was found to be $6.6168 \mathrm{~g} / 100 \mathrm{~g}$ which falls in the range as recommended for algal products sold in the USA ( $45 \%$ dry weight) [17]. Table 2 represents that to determine the levels of macro as well as micronutrients such as sodium (Na), potassium (K), phosphorus (P), calcium (Ca), and magnesium (Mg); trace elements included zinc (Zn), iron (Fe), manganese (Mn), and copper (Cu) in C. emersonii KJ725233.

When compared with values of commercial products, it is evident that the isolate once again stands apart from the existing ones. Its calcium content was eight folds higher as compared to that reported for another Chlorella species. On the other hand, phosphorus was fourfold, and magnesium was found to be six folds greater than that reported for the Chlorella species [17]. Similarly, a tenfold difference in potassium content with that reported for Chlorella species was also observed [18]. Thus, the consumption of C. emersonii KJ725233 could overall contribute to the essential mineral requirements of the body.

\section{Antioxidant properties of $C$. emersonii KJ725233}

The total antioxidant potential of C. emersonii KJ725233 was determined by the phosphomolybdenum assay based on the reduction of Mo (IV) to Mo (V) by the sample to form a green phosphate/Mo complex with a maximum absorption at $695 \mathrm{~nm}$ [27]. The phosphomolybdenum

Table 2: Mineral composition of C. emersonii KJ725233

\begin{tabular}{ll}
\hline Mineral & mg/100 gDW \\
\hline $\mathrm{Na}$ & $0.76 \pm 0.04$ \\
$\mathrm{~K}$ & $0.46 \pm 0.05$ \\
$\mathrm{P}$ & $0.87 \pm 0.03$ \\
$\mathrm{Ca}$ & $2.77 \pm 0.24$ \\
$\mathrm{Mg}$ & $0.61 \pm 0.03$ \\
$\mathrm{Zn}$ & $0.03 \pm 0.01$ \\
$\mathrm{Fe}$ & $0.15 \pm 0.03$ \\
$\mathrm{Mn}$ & $0.8 \pm 0.02$ \\
$\mathrm{Cu}$ & $0.02 \pm 0.002$ \\
\hline
\end{tabular}

Values are expressed as mean \pm SD for triplicate experiments. Values are significant at $\mathrm{P}<0.05$. C. emersonii: Chlorella emersonii method measures the antioxidant activity due to phenolics, ascorbic acid, $\alpha$-tocopherol, carotenoids, butylhydroxytoluene as well as reduced glutathione $[22,28]$. Table 3 shows the antioxidant capacity of the different solvent extracts wherein it can be seen that the maximum activity of $22.4 \pm 0.1 \mathrm{mg} / \mathrm{g}$ is exhibited by chloroform extract whereas ethyl acetate shows the least antioxidant potential of $8.49 \pm 0.51 \mathrm{mg} / \mathrm{g} \mathrm{AAE}$.

The reducing power for the extracts was determined by their ability to reduce $\mathrm{Fe}^{+3}$ to $\mathrm{Fe}^{+2}$ by the action of antioxidants. The water extract exhibited highest reducing power, i.e., $14.86 \pm 0.60 \mathrm{mg} / \mathrm{g}$ AAE whereas the least was shown by chloroform extract, i.e., $8.08 \pm 0.12 \mathrm{mg} / \mathrm{g}$ AAE. The reducing power for methanolic extract of $C$. emersonii KJ725233 was found to be $11.02 \pm 0.35 \mathrm{mg} / \mathrm{g}$ AAE which is twenty folds higher as compared to $0.562 \pm 0.172$ and $0.73 \pm 0.026 \mathrm{mg} / \mathrm{g}$ AAE reported for methanolic extract of Chlorella marina [23,29].

The hydrogen donating ability of the extracts on DPPH leads to a loss of violet color forming the reduced substance DPPH (non-radical) [30]. $\mathrm{IC}_{50}$ values for the different extracts were calculated by plotting a graph of percent radical scavenging against the concentrations of the extract (2-10 mg) and are represented in Table 2 . The $\mathrm{IC}_{50}$ is inversely proportional to the antioxidant activity, i.e., the lower the $\mathrm{IC}_{50}$, the greater is the antioxidant potential of the extract. Phenols and flavonoids have the ability to donate their hydrogen and thus function as strong free radical scavengers [31]. Methanolic extract, thus, exhibited the lowest $\mathrm{IC}_{50^{\prime}}$, i.e., $6.59 \pm 0.33 \mathrm{mg} / \mathrm{ml}$ as compared to the other solvent extracts. This, thus, correlates to the concentration of phenols and flavonoids in the methanolic extract as compared to the other solvent extracts. The $\mathrm{IC}_{50}$ for the aqueous extract of $C$. emersonii KJ725233 was found to be $7.55 \pm 0.09 \mathrm{mg} / \mathrm{ml}$ dried biomass which is less than that reported for commercially available tablets of Chlorella pyrenoidosa (Sun chlorella), i.e., $9.62 \mathrm{mg} / \mathrm{ml}$ as earlier reported [32].

Total phenolic as well as flavonoid content of C. emersonii KJ725233 different organic extracts is shown in Table 3 . The yield varied with the different organic solvents used for the extraction aqueous extracts showed a higher amount of phenols $6.60 \pm 0.06 \mathrm{mg} / \mathrm{g} \mathrm{GAE}$ as compared to organic extracts, for which the phenolic content ranged from $2.20 \pm 0.21$ to $5.19 \pm 0.10 \mathrm{mg} / \mathrm{g}$ GAE. C. emersonii KJ 725233 contains an appreciable amount of phenols wherein the phenolic content in the methanolic extract $5.19 \pm 0.10 \mathrm{mg} / \mathrm{g} \mathrm{GAE}$ is eight folds higher than that reported for the methanolic extract of C. marina $0.647 \mathrm{mg} / \mathrm{g}$ GAE [29]. In the present investigation, the total flavonoid content ranged from $1.20 \pm 0.09$ to $24.60 \pm 1.18 \mathrm{mg} / \mathrm{g}$ quercetin equivalence.

\section{Antimicrobial activity}

The antimicrobial activity of the solvent extracts of $C$. emersonii KJ725233 was evaluated against selected bacterial as well as fungal clinical isolates by the agar well-diffusion method. Except the aqueous, all the organic extracts exhibited considerable antimicrobial activity ranging from $11.46 \pm 0.15$ to $19.36 \pm 0.51 \mathrm{~mm}$ against selected bacteria as well as the yeast while no effect on other fungal species as seen in Table 4. Results indicated that the methanolic, chloroform, and ethyl acetate extracts were effective against both Gram-positive as well

Table 3: Comparison of the antioxidant activity (TAC, FRAP and DPPH), total phenolic content and total flavonoid content of $C$. emersonii KJ725233 in different solvents

\begin{tabular}{lllll}
\hline Solvents & TAC $^{\mathbf{a}}$ & FRAP $^{\mathbf{b}}$ & DPPH $^{\mathbf{c}}$ & TPC $^{\mathbf{d}}$ \\
\hline Water & $17.53 \pm 0.35$ & $14.86 \pm 0.60$ & $7.8 \pm 0.08$ & $6.60 \pm 0.06$ \\
Methanol & $16.8 \pm 0.26$ & $11.02 \pm 0.35$ & $6.59 \pm 0.33$ & $1.20 \pm 0.09$ \\
Acetone & $13.63 \pm 1.33$ & $8.20 \pm 1.13$ & $13.82 \pm 0.35$ & $2.19 \pm 0.10$ \\
Chloroform & $22.4 \pm 0.1$ & $8.08 \pm 0.12$ & $6.98 \pm 0.80$ & $2.20 \pm 0.21$ \\
Ethyl acetate & $8.49 \pm 0.51$ & $9.53 \pm 0.38$ & $16.25 \pm 0.73$ & $4.624 \pm 0.31$ \\
Diethyl ether & $11.9 \pm 0.44$ & $8.59 \pm 0.51$ & $13.38 \pm 0.25$ & $2.75 \pm 0.19$ \\
\hline
\end{tabular}

Values are expressed as mean \pm standard deviation for triplicate experiments. Values are significant at P $<0.05$. ${ }^{\mathrm{a} T A C}$ expressed as mg AAE/g DW, ${ }^{\mathrm{b}} \mathrm{FRAP}$ expressed as mg

$\mathrm{AAE} / \mathrm{g}$ DW, ${ }^{\mathrm{D} P P H}$ : IC50 expressed as $\mathrm{mg}{ }^{\mathrm{D} W} / \mathrm{ml}$, ${ }^{\mathrm{d}}$ Total phenolic content expressed as $\mathrm{mg} \mathrm{GAE} / \mathrm{g}$ DW, ${ }^{\mathrm{e} T o t a l}$ flavonoids expressed as mg QE/g DW 
as Gram-negative organisms with a zone of inhibition ranging from $11.46 \pm 0.15 \mathrm{~mm}$ to $15.36 \pm 0.45 \mathrm{~mm}$, whereas the acetone extract and the diethyl ether extract showed activity only against the Gram-positive and Gram-negative organisms, respectively. This could be attributed to the presence of antimicrobial compounds such as phytol, hexadecane, and 1-docosene in methanolic, chloroform, and ethyl acetate extracts as reported in Table 5. The inability of the acetone extract to inhibit the growth Gram-negative and diethyl ether extract to inhibit Gram-positive

Table 4: Comparison of the antimicrobial activity of $C$. emersonii KJ725233 in different solvents

\begin{tabular}{|c|c|c|c|c|c|c|}
\hline $\begin{array}{l}\text { Extracts/ } \\
\text { control }\end{array}$ & $\begin{array}{l}\text { B. subtilis MTCC } \\
441\end{array}$ & $\begin{array}{l}\text { E. coli MTCC } \\
443\end{array}$ & $\begin{array}{l}\text { P. aeruginosa MTCC } \\
1688\end{array}$ & $\begin{array}{l}\text { S. aureus MTCC } \\
6908\end{array}$ & $\begin{array}{l}\text { C. albicans MTCC } \\
227\end{array}$ & $\begin{array}{l}\text { A. niger MTCC } \\
1344\end{array}$ \\
\hline Methanol & $11.46 \pm 0.15$ & $12.56 \pm 0.20$ & $15.3 \pm 0.36$ & $13.8 \pm 0.3$ & $18.1 \pm 0.86$ & - \\
\hline Acetone & $12.23 \pm 0.35$ & - & - & $19.36 \pm 0.51$ & $14.3 \pm 0.66$ & - \\
\hline Chloroform & $11.66 \pm 0.51$ & $13.83 \pm 0.25$ & $15.36 \pm 0.45$ & $12.46 \pm 0.25$ & $13.66 \pm 0.57$ & - \\
\hline Ethyl acetate & $14.23 \pm 0.35$ & $12.5 \pm 0.4$ & $12.5 \pm 0.4$ & $13.06 \pm 0.15$ & $16.42 \pm 0.59$ & - \\
\hline Diethyl ether & - & $12.4 \pm 0.36$ & $11.13 \pm 0.15$ & - & $12.8 \pm 0.32$ & - \\
\hline Gentamycin $^{\mathrm{a}}$ & $22.23 \pm 0.25$ & $25.66 \pm 0.58$ & $25 \pm 0.1$ & $30.33 \pm 0.58$ & NA & NA \\
\hline $\mathrm{DMSO}^{\mathrm{c}}$ & - & - & - & - & - & - \\
\hline
\end{tabular}

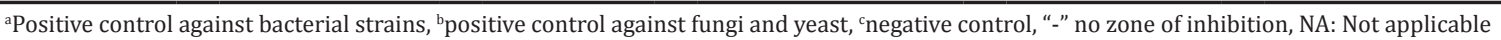

Table 5: Bioactives extracted in different organic solvent extracts of $C$. emersonii KJ725233

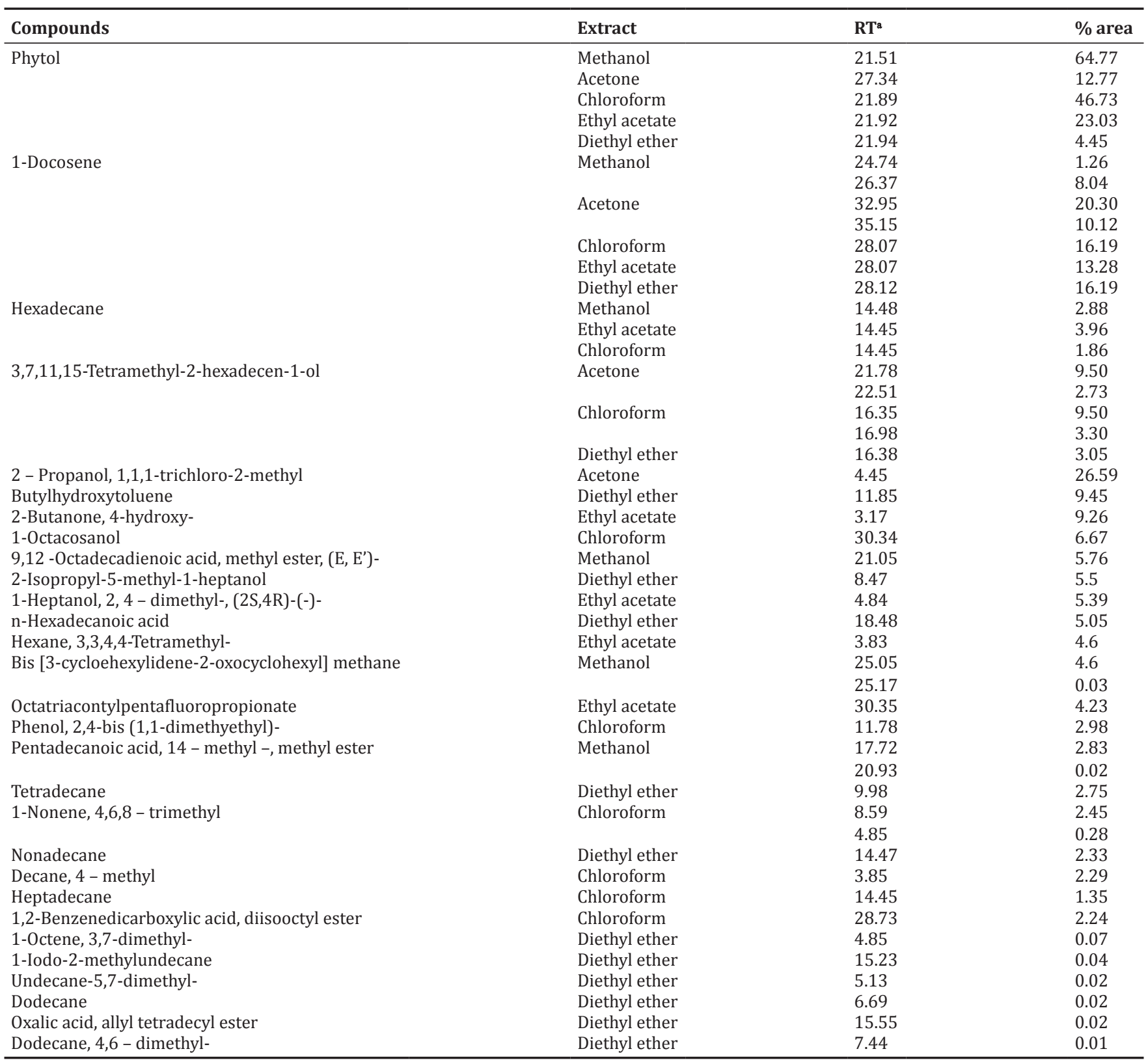

aRetention time in minutes 
could be due to the absence of hexadecane in these extracts (Table 5). The synergistic and antagonistic effect of the bioactives may play a role in the antimicrobial potential, and hence the presence of hexadecane may be mandatory for the extracts to be antibacterial against both Gram-positive as well as Gram-negative bacteria. Since the positive controls were broad-spectrum antibiotics, their antimicrobial activity against the tested micro-organisms was more as compared to that of the crude algal extracts.

\section{GC-HRMS analysis of crude organic extracts of $C$. emersonii KJ725233}

HRMS analysis is reported to provide twice the identification as compared to that of a low-resolution mass spectrometer [33]. Hence, even though gas chromatography-mass spectrometry (GC-MS) has been used to analyze biomass of micro as well as macroalgae, the present study utilized GC-HRMS for the purpose of analysis [32,34].

In the present study, 29 compounds were identified in the five different organic extracts as presented in Table 5. However, a majority of them (seventeen) contributed $<5 \%$ to the total peak area of the respective chromatograms, and hence only the major compounds are referred herewith. Of these compounds, phytol and 1-docosene were common in all the organic extracts. Phytol, a major contributor (12-65\%) of all the organic extracts, has been reported to be an antioxidant, antimicrobial, anti-inflammatory, anticancer, diuretic, anti-malarial as well as antimycobacterial whereas 1-docosene is a known anticancer as well as antimicrobial [35-38]. Hexadecane identified in methanol, chloroform, and ethyl acetate extracts is reported for antibacterial as well as antioxidant activities [39]. Butyl hydroxyl toluene, an excellent antioxidant, contributed $9.45 \%$ to the diethyl ether extract [40]. A variant of phytol, 3,7,11,15-tetramethyl-2-hexadecen-1-ol has contributed about $2.73-9.5 \%$ in acetone, chloroform and diethyl ether extract. This compound is known antimicrobial as well as anti- inflammatory in nature [41].

In addition to these, a phenolic antioxidant, phenol,2,4- bis(1,1- dimethylethyl)-, identified in the chloroform extract is reported as an ultraviolet stabilizer as well as an antioxidant for hydrocarbon- based products such as the plastic coatings used for food packaging [42]. Phenol,2,4-bis(1,1-dimethyethyl)- has been identified as an additive in plastic packaging like Hostanox PAR 24 FF by GC-MS analysis [43]. 1,2-Benzenedicarboxylic acid, diisooctyl ester - another plasticizer was also detected in the chloroform extract [44].

In the present study, the acetone extract revealed an unusual peak of 2-propanol, 1,1,1-trichloro-2-methyl (chloretone) with a retention time $4.45 \mathrm{~min}$ that contributes to the extent of $26 \%$ of the total peak area. Chloretone is reported to have a mild anesthetic potential in addition to, the antibacterial as well as germicidal effect and hence used in pharmaceutical formulations. Literature reports the chemical synthesis of this compound by addition of chloroform and acetone in the presence of powdered potassium hydroxide as a catalyst [45]. Production of chloroform by microalgae under conditions of hypochlorite stress at temperatures $20^{\circ} \mathrm{C}$ and $25^{\circ} \mathrm{C}$ as well as under alkaline conditions is reported [46]. Production of chloroform by freshwater Chlorella species and blue green alga Anabaena flos-aquae has also been reported by Wachter and Andelman, 1984. [47]. Therefore, with the growth conditions employed for the present study, Chlorella might have synthesized chloroform which is further converted to chloretone during the extraction with acetone. This is further supported by the fact that the compound is detected only in the acetone extract and none of the other solvents. This hypothesis, however, requires a further extensive study to investigate the regulation of chloroform synthesis in C. emersonii KJ725233.

\section{CONCLUSION}

With economically attractive growth conditions, non-fastidious growth characteristics, and a commercially attractive nutrient profile C. emersonii KJ725233 presents itself as an inexpensive, commercially exploitable source of bioactives with potential applications in food industry. The nutritional as well as biological profile of this isolate when compared to existing commercial Chlorella powders as well as the wild type Chlorella strains reported in literature, clearly indicates the advantage of this isolate not only as protein-lipid but also as an antioxidant and antimicrobial source. The strain, thus, harbors a potential to substitute their synthetic equivalents currently used. Its use, therefore, as a potential food supplement and/or as a complete food would be able to improve bodily functions enhancing animal health.

\section{AUTHOR'S CONTRIBUTION}

Ms. Sneha Sunil Sawant - Experimentation, Results evaluation, Manuscript writing, Editing, final manuscript approval.

Dr. Mrs. Varsha Kelkar Mane - Experiment designing, result evaluations, manuscript revisions, final manuscript approval.

\section{CONFLICT OF INTEREST}

The authors declare no conflict of interest.

\section{REFERENCES}

1. Masojidek J, Torzillo G. Mass cultivation of freshwater microalgae. In: Sven EJ, editor. Applications of Ecological Engineering. London: Elsevier Science and Technology; 2009. p. 176-85.

2. Bishop WM, Zubeck HM. Evaluation of microalgae for use as nutraceuticals and nutritional supplements. J Nutr Food Sci 2012;2:1-6.

3. Priyadarshani I, Rath B. Commercial and industrial applications of microalgae-A review. J Algal Biomass Utln 2012;3:89-100.

4. Kent M, Welladsen HM, Mangott A, Li Y. Nutritional evaluation of Australian microalgae as potential human health supplements. PLoS One 2015;10:e0118985.

5. Guccione A, Biondi N, Sampietro G, Rodolfi L, Bassi N, Tredici MR, et al. Chlorella for protein and biofuels: From strain selection to outdoor cultivation in a green wall panel photobioreactor. Biotechnol Biofuels 2014;7:84.

6. Gouveia L, Batista AP, Sousa I, Raymundo A, Bandarra NM. Microalgae in novel food product. In: Konstantinos NP, editor. Food Chemistry Research Developments. New York: Nova Science Publishers; 2008. p. $75-112$

7. Wong CY, Teoh ML, Phang SM, Lim PE, Beardall J. Interactive effects of temperature and UV radiation on photosynthesis of Chlorella strains from polar, temperate and tropical environments: Differential impacts on damage and repair. PLoS One 2015;10:e0139469.

8. $\mathrm{Xu} \mathrm{J}, \mathrm{Hu} \mathrm{H}$. Screening high oleaginous chlorella strains from different climate zones. Bioresour Technol 2013;144:637-43.

9. Bewicke D, Potter AB. Chlorella-The Emerald Food. Berkeley: Ronin Publishing Inc; 1984

10. Ahn JW, Hwangbo K, Lee SY, Choi HG, Park YI, Liu JR, et al. A new arctic Chlorella species for biodiesel production. Bioresour Technol 2012;125:340-3.

11. Hoek C, Mann DG, Jahns HM. Algae: An Introduction to Phycology. UK; Cambridge University Press; 1995.

12. Hu H, Li H, Xu X. Alternative cold response modes in Chlorella (Chlorophyta, Trebouxiophyceae) from Antarctica. Phycologia 2008a;47:28-34.

13. Najdenski HM, Gigova LG, Iliev II, Pilarski PS, Lukavský J, Tsvetkova IV, et al. Antibacterial and antifungal activities of selected microalgae and Cyanobacteria. Int J Food Sci Technol 2013;48:1533- 40

14. Sawant SS, Joshi A, Bhagwat A, Kelkar-Mane A. Tapping the antioxidant potential of a novel isolate-Chlorella emersonii KJ725233. World J Pharm Res 2014;3:726-39.

15. Gouveia L, Batista AP, Miranda A, Empis J, Raymundo A. Chlorella vulgaris biomass used as colouring source in traditional butter cookies. Innov Food Sci Emerg Technol 2007;8:433-6

16. Sharma R, Singh GP, Sharma VK. Effects of culture conditions on growth and biochemical profile of Chlorella. J Plant Pathol Microbiol 2012;3:1-6.

17. Tibbetts SM, Melanson RJ, Park KC, Banskota AH, Stefanova R, Mcginn PJ. Nutritional evaluation of whole and lipid-extracted biomass of the microalga Scenedesmus sp. AMDD Isolated in Saskatchewan, Canada for Animal Feeds : Proximate, Amino Acid, Fatty Acid, Carotenoid and 
Elemental Composition. Curr Biotechnol 2015;4:530- 46.

18. Tokusoglu O, Unal MK. Biomass nutrient profiles of three microalgae: Spirulina platensis, Chlorella vulgaris and Isochrysis galbana. J Food Sci 2003;68:1144-8.

19. Ming LC, Nurliyana R, Syah AB, Azizah MN, Sim HL, Hirzun MY. Identification and biochemical composition of a green microalgae. Asian J Biotechnol 2012;4:38-45.

20. Folch J, Lees M, Sloane SG. A Simple method for the isolation and purification of Total lipides from animal tissues. J Biol Chem 1957;226:497-509.

21. Zhao G, Chen X, Wang L, Zhou S, Feng H, Chen WN, et al. Ultrasound assisted extraction of carbohydrates from microalgae as feedstock for yeast fermentation. Bioresour Technol 2013;128:337-44.

22. Prieto P, Pineda M, Aguilar M. Spectrophotometric quantitation of antioxidant capacity through the formation of a phosphomolybdenum complex: Specific application to the determination of vitamin E. Anal Biochem 1999;269:337-41.

23. Hemalatha A, Girija K, Parthiban C, Saranya C, Anantharaman P. Antioxidant properties and total phenolic content of a marine diatom, Navicula clavata and green microalgae, Chlorella marina and Dunaliella salina. Adv App Sci Res 2013;4:151-7.

24. Bendaoud H, Bouajila J, Rhouma A, Romdhane M. GC/MS analysis and antimicrobial and antioxidant activities of essential oil of Eucalyptus radiata. J Sci Food Agric 2009;89:1292-7.

25. Wu LC, Ho JA, Shieh MC, Lu IW. Antioxidant and antiproliferative activities of Spirulina and Chlorella water extracts. J Agric Food Chem 2005;53:4207-12.

26. Ibibia EK. Spectroscopic determination of total phenolic and total flavonoid contents, the antioxidant activity of the leaves of Persea americana. Int J Pharm Pharm Sci 2013;5:598-603.

27. Chung IM, Ali M, Nagella P, Ahmad A. New glycosidic constituents from fruits of Lycium chinense and their antioxidant activities. Arab J Chem 2015;8:803-11.

28. Apak R, Güçlü K, Demirata B, Ozyürek M, Celik SE, Bektaşoğlu B, et al. Comparative evaluation of various total antioxidant capacity assays applied to phenolic compounds with the CUPRAC assay. Molecules 2007;12:1496-547.

29. Manivannan K, Anantharaman P, Balasubramanian T. Evaluation of antioxidant properties of marine microalga Chlorella marina (Butcher, 1952). Asian Pac J Trop Biomed 2012;2:S342-6.

30. Oke F, Aslim B, Ozturk S, Altundag S. Essential oil composition, antimicrobial and antioxidant activities of Satureja cuneifolia Ten. Food Chem 2009;112:874-9.

31. Ahmed D, Fatima K, Saeed R. Analysis of phenolic and flavonoid contents, and the anti-oxidative potential and lipid peroxidation inhibitory activity of methanolic extract of Carissa opaca roots and its fractions in different solvents. Antioxidants (Basel) 2014;3:671-83.

32. Geetha BV, Navasakthi R, Padmini E. Investigation of antioxidant capacity and phytochemical composition of sun Chlorella -An in vitro Study. J Aquac Res Dev 2010;1:1-7.

33. Lebedev AT, Polyakova OV, Mazur DM, Artaev VB. The benefits of high resolution mass spectrometry in environmental analysis. Analyst 2013; 138:6946-53

34. Sathya S, Srisudha S, Gunasekaran P. Growth rate, pigment composition and fatty acid profile of Chlorella pyrenoidosa. Int J Biol Pharm Res 2012;3:677-83.

35. Rajab MS, Cantrell CL, Franzblau SG, Fischer NH. Antimycobacterial activity of (E)-phytol and derivatives: A preliminary structure-activity study. Planta Med 1998;64:2-4.

36. Jain SC, Pancholi B, Jain R. Antimicrobial, free radical scavenging activities and chemical composition of Peltophorum pterocarpum Baker ex K. Heyne stem extract. Der Pharm Chem 2012;4:2073-9.

37. Krishnamoorthy K, Subramaniam P. Phytochemical profiling of leaf, stem, and tuber parts of Solena amplexicaulis (Lam.) Gandhi using GC- MS. Int Sch Res Notices 2014;2014:567409.

38. Dandekar R, Fegade B, Bhaskar VH. GC-MS analysis of phytoconstituents in alcohol extract of Epiphyllum oxypetalum leaves. J Pharm Phytochem 2015;4:149-54.

39. Yogeswari S, Ramalakshmi S, Neelavathy R, Muthumary J. Identification and comparative studies of different volatile fractions from Monochaetia kansensis by GCMS. Glob J Pharmacol 2012;6:65- 71.

40. Karamac M, Amarowicz R. Antioxidant activity of BHA, BHT and TBHQ examined with Miller's test. Grasas Aceites 1997;48:83-6.

41. Venkata RB, Samuel LA, Pardha SM, Narashimha RB, Naga VK, Sudhakar M, et al. Antibacterial, antioxidant and GCMS analysis of Eupatorium odoratum. Asian J Pharm Clin Res 2012;5:99-106.

42. Govindappa M, Prathap S, Vinay V, Channabasava R. Chemical composition of methanol extract of endophytic fungi, Alternaria sp. of Tebebuia argente $a$ and their antimicrobial and antioxidant activity. Int $\mathrm{J}$ Biol Pharm Res 2014;5:861-9.

43. Lahimer MC, Ayed N, Horriche J, Belgaied S. Characterization of plastic packaging additives : Food contact, stability and toxicity. Arab J Chem 2017;10:S1938-54.

44. Priyadharshini SD, Sujatha V. Antioxidant profile and GC-MS analysis of Solanum erianthum leaves and stem-a comparison. Int J Pharm Pharm Sci 2013;5:652-8.

45. Saljoughian M, Raisi A, Alipour E, Afshar S. An improved synthesis of 1,1,1-trichloro-2-methyl-2-propanol (chlorobutanol). Monatsh Chem 1983;114:813-6.

46. Borges JT, Sparrapan R, Guimarães JR, Eberlin MN, Augusti R. Chloroform formation by chlorination of aqueous algae suspensions: Online monitoring via membrane introduction mass spectrometry. J Braz Chem Soc 2008; 19:950-5.

47. Wachter JK, Andelman JB. Organohalide formation on chlorination of algal extracellular products. Environ Sci Technol 1984;18:811-7. 